\title{
Cana-de-açúcar em substituição à silagem de milho em dietas para vacas em lactação: parâmetros digestivos e ruminais ${ }^{1}$
}

\author{
André Luiz Rodrigues Magalhães ${ }^{2}$, José Maurício de Souza Campos ${ }^{3}$, Luciano da Silva \\ Cabral $^{4}$, Renius Mello ${ }^{5}$, José Antônio de Freitas ${ }^{6}$, Robledo de Almeida Torres ${ }^{3}$, Sebastião de \\ Campos Valadares Filho ${ }^{3}$, Anderson Jorge de Assis 5
}

\author{
1 Parte da dissertação de Mestrado do primeiro autor apresentada ao Departamento de Zootecnia da UFV. \\ 2 Faculdade de Medicina Veterinária - Universidade de Cuiabá. \\ ${ }^{3}$ Departamento de Zootecnia - Universidade Federal de Viçosa. \\ ${ }^{4}$ Departamento de Zootecnia e Extensão Rural da UFMT. \\ 5 Pós-graduação em Zootecnia - Universidade Federal de Viçosa. \\ ${ }^{6}$ Universidade Federal do Paraná - Campus Palotina.
}

RESUMO - O experimento foi realizado com o objetivo de avaliar a substituição da silagem de milho por cana-de-açúcar em dietas para vacas leiteiras. Foram avaliados quatro níveis de substituição $(0 ; 33,3 ; 66,6$ e $100 \%)$ de silagem de milho por cana-de-açúcar para o estudo do consumo e da digestibilidade aparente dos nutrientes e a determinação do pH e da concentração de compostos nitrogenados amoniacais $\left(\mathrm{N}_{-} \mathrm{NH}_{3}\right)$ do líquido ruminal e da taxa de passagem ruminal da digesta. Doze vacas da raça Holandesa, puras e mestiças, com potencial para produção de 5.000 a $7.000 \mathrm{~kg}$ de leite por lactação, foram distribuídas em três quadrados latinos 4 × 4 balanceados, conforme o período de lactação. Os animais foram mantidos em baias individuais, onde receberam as dietas (ad libitum), duas vezes ao dia, com relação volumoso:concentrado 60:40, durante 84 dias experimentais. $\mathrm{O}$ aumento do nível de substituição de silagem de milho por cana-de-açúcar promoveu redução linear do consumo de todos os nutrientes, exceto lignina e carboidratos não-fibrosos. A substituição não afetou as digestibilidades da matéria seca, da matéria orgânica e da proteína bruta. A digestibilidade da fibra em detergente neutro apresentou redução acentuada, enquanto a dos carboidratos não-fibrosos aumentou. $\mathrm{O} \mathrm{pH}$ ruminal não foi influenciado pelas dietas, apresentando comportamento quadrático conforme o tempo após alimentação. As concentrações de amônia ruminal apresentaram comportamento quadrático de acordo com as dietas e o tempo de alimentação. A taxa de passagem ruminal da digesta diminuiu e o tempo médio de retenção total aumentou com a substituição, o que pode explicar a redução no consumo. A silagem de milho pode ser substituída em até $33 \%$ pela cana-de-açúcar para vacas com produções médias diárias de $24 \mathrm{~kg}$ de leite.

Palavras-chave: consumo, digestibilidade, $\mathrm{pH}$ e amônia ruminais

\section{Effects of replacing corn silage with sugarcane on production and ruminal metabolism of lactating dairy cows}

\footnotetext{
ABSTRACT - This trial was conducted to evaluate the effects of replacing corn silage with sugarcane on intake, apparent digestibility of nutrients, ruminal $\mathrm{pH}$ and ammonia nitrogen, and ruminal passage rate of digesta in lactating dairy cows. Proportion sugarcane increased as follows: $0,33.3,66.6$ and 100\% of the forage portion of the diet. Twelve Holstein and crossbred Holstein/Zebu cows with potential yield varying from 5,000 to 7,000 $\mathrm{kg}$ of milk per lactation were randomly assigned to three $4 \times 4$ Latin squares. Cows were maintained in individual stalls and were fed ad libitum twice a day a diet containing a forage:concentrate ratio of 60:40 during the 84-days experimental period. Replacing corn silage with sugarcane linearly reduced the intakes of all nutrients with the exception of lignin and nonfiber carbohydrates. No significant effects on apparent digestibilities of dry matter, organic matter and crude protein were observed by replacing corn silage with sugarcane in this trial. However, neutral detergent fiber digestibility decreased and that of nonfiber carbohydrates increased when sugarcane replaced corn silage in the diet. Although ruminal $\mathrm{pH}$ did not differ among treatments, a significant quadratic response was found according to time after feeding. Significant quadratic responses were also observed for concentration of ruminal ammonia by increasing the proportion of sugarcane in the diet as well as time past the morning feeding. Ruminal passage rate of digesta decreased and average total retention time increased as sugarcane replaced corn silage, which possibly explains the observed reduction in dry matter intake. Therefore, it is recommended to include up to $33 \%$ of sugarcane in the diet of lactating dairy cows yielding $24 \mathrm{~kg}$ of milk per day.
}

Key Words: intake, digestibility, ruminal $\mathrm{pH}$, ruminal ammonia 


\section{Introdução}

O problema mais freqüente em rebanhos de alta produção de leite é a incapacidade dos animais em consumir quantidade suficiente para satisfazer suas elevadas exigências nutricionais.

Segundo Preston (1982), quando o consumo voluntário é baixo, o turnover do fluido ruminal também é baixo. As forrageiras tropicais, ou seja, aquelas pertencentes ao grupo $\mathrm{C}_{4}$, apresentam, em razão de suas características anatômicas e químicas particulares, a fibra mais resistente ao ataque dos microrganismos ruminais, o que ocasiona maior tempo de permanência desta fração no rúmen e, conseqüentemente, redução do consumo voluntário pelos animais (Matos, 1995).

Além do consumo, deve-se avaliar também o conteúdo energético dos alimentos fornecidos para ruminantes, que apresenta elevada correlação com a digestibilidade dos nutrientes (Kitessa et al., 1999), a qual permite que o animal utilize os nutrientes em maior ou menor escala. Em ruminantes, a fibra é responsável pela grande variação na digestibilidade dos alimentos volumosos, pois geralmente apresenta relação negativa com a digestibilidade (Van Soest, 1967).

Para que ocorra eficiente utilização dos nutrientes pelos ruminantes, as condições ecológicas dentro do rúmen devem ser mantidas dentro de certos limites, para garantir crescimento e metabolismo microbianos ruminais normais (Van Soest, 1994). O pH ruminal, a concentração de amônia e a taxa de passagem da digesta exercem marcado efeito na eficiência microbiana no tipos de microrganismos existentes e na disponibilidade de energia (Russell, 1997).

O nível de consumo, o tempo após a alimentação, a natureza da dieta e a salivação têm efeito direto sobre o pH do rúmen (Queiroz et al., 1998), enquanto as concentrações de amônia $\left(\mathrm{N}-\mathrm{NH}_{3}\right)$ no rúmen são utilizadas como indicadores do metabolismo dos compostos nitrogenados, visto que a amônia é a principal fonte de nitrogênio para a síntese protéica microbiana (Wallace et al., 1997).

A taxa na qual a digesta se move ao longo do trato gastrintestinal, a taxa de fermentação do alimento e a quantidade de matéria seca (MS) consumida são os principais fatores que determinam a proporção que determinado nutriente será digerido, absorvido e utilizado pelo animal (Colucci et al., 1982). Uma alteração em qualquer um desses três fatores geralmente muda os outros dois, o que demonstra a relevância biológica da taxa de passagem.

Entre as forrageiras tropicais, a cana-de-açúcar destaca-se principalmente por sua elevada produtividade e boa qualidade na época seca do ano, contrastando com as demais forrageiras deste grupo. Entretanto, o fornecimento de cana-de-açúcar para animais de elevada exigência nutricional, como vacas leiteiras em lactação, tem causado redução do consumo de MS e da produção de leite (Valvasori et al., 1995; Magalhães et al., 2004; Mendonça et al., 2004), de modo que o efeito sobre o consumo tem sido atribuído à baixa qualidade de sua fibra. Contudo, ainda existem poucos dados sobre esses parâmetros em vacas leiteiras em lactação.

Este trabalho foi realizado com o objetivo de avaliar os efeitos da substituição de $0 ; 33,3 ; 66,6$ e $100 \%$ da silagem de milho por cana-de-açúcar (na MS) sobre a digestibilidade aparente dos nutrientes, o pH e a concentração de amônia do líquido ruminal e a taxa de passagem da digesta ruminal em vacas em lactação com produções médias diárias acima de $20 \mathrm{~kg}$ de leite.

\section{Material e Métodos}

O experimento foi conduzido no Departamento de Zootecnia da Universidade Federal de Viçosa (UFV), em ViçosaMG. Foram utilizadas 12 vacas da raça Holandesa, puras e mestiças, com potencial de produção de 5.000 a $7.000 \mathrm{~kg}$ de leite por lactação. Os animais foram distribuídos em três quadrados latinos 4 x 4, balanceados de acordo com o período de lactação, que foram, em média, de 34, 49 e 76 dias, para o primeiro, segundo e terceiro quadrados latinos, respectivamente, no início do experimento. Trinta dias antes do parto, as vacas foram manejadas para apresentar condição corporal ao parto de 3,5 na escala de 1 a 5 (Ferreira \& Torres, 1993).

O experimento teve duração de 84 dias e foi dividido em quatro períodos de 21 dias; os sete primeiros destinados à adaptação dos animais às dietas e os demais, à coleta de amostras. No início do experimento, as vacas foram transferidas para baias individuais e a alimentação foi fornecida duas vezes ao dia ( 8 e $16 \mathrm{~h}$ ) logo após as ordenhas. Os animais receberam dietas completas ad libitum, contendo $0 ; 33,3 ; 66,6$ e 100\% de cana-de-açúcar (variedade SP801842) em substituição à silagem de milho.

Os alimentos concentrados utilizados no balanceamento das dietas foram milho, farelo de soja, uréia, fosfato bicálcico, calcário, sal comum e premix mineral. As dietas foram formuladas para atender às exigências de $\mathrm{PB}$, proteína degradável no rúmen (PDR), EE, NDT, vitamina A, macro e microminerais, segundo o NRC (1989), e de FDN, segundo Mertens (1996), de forma que fossem isonitrogenadas e com o mesmo teor de nitrogênio não-protéico (NNP).

Os concentrados foram rigorosamente misturados aos volumosos na proporção de 40:60, respectivamente, com base na MS. Na Tabela 1, são apresentadas as proporções dos ingredientes nas dietas experimentais. O consumo de 
alimentos foi monitorado diariamente para que houvesse sobras em torno de $10 \%$, com base na MS, as quais foram retiradas dos cochos duas vezes ao dia. As amostragens dos alimentos volumosos e das sobras foram feitas diariamente nos nove últimos dias de cada período experimental, enquanto os concentrados foram amostrados por lote misturado na fábrica de ração.

Os carboidratos totais (CT) dos concentrados, dos volumosos e das dietas foram calculados como: $\% \mathrm{CT}=100$ - $(\% \mathrm{~PB}+\% \mathrm{EE}+\% \mathrm{MM})$ e o NDT como: NDT $=\mathrm{PBD}+$ 2,25EED + CTD, segundo Sniffen et al. (1992), em que: MM $=$ matéria mineral $; \mathrm{PBD}=$ proteína bruta digestível $; \mathrm{EED}=$ extrato etéreo digestível; CTD = carboidratos totais digestíveis.

A digestibilidade da MS e dos demais nutrientes foi determinada utilizando-se a da fibra em detergente ácido indigestível (FDAi) como indicador interno, a qual foi determinada pela incubação in situ dos alimentos, das sobras e das fezes durante 144 horas, segundo técnica descrita por Cochran et al. (1986). As coletas de amostras fecais foram feitas diretamente no reto dos animais, duas vezes ao dia, durante os últimos cinco dias de cada período experimental. Ao final de cada período, as amostras foram pré-secas e formaram uma amostra composta por animal e por período.

Para determinação do $\mathrm{pH}$ e da concentração de amônia $\left(\mathrm{N}-\mathrm{NH}_{3}\right)$ no líquido ruminal, as amostras foram obtidas utilizando-se sonda esofágica, segundo técnica descrita por Ortoloni (1981), largamente utilizada para retirada de fluido ruminal em animais não-fistulados (Lavezzo et al., 1988). As amostras foram coletadas imediatamente antes (zero hora) e 2, 4 e 6 horas após a refeição da manhã, no 12 o dia de cada período experimental, sendo filtradas para determinação imediata do $\mathrm{pH}$ em potenciômetro digital. A partir deste filtrado, retirou-se uma alíquota de $40 \mathrm{~mL}$, a qual foi adicionada de $1 \mathrm{~mL}$ de ácido sulfúrico a $50 \%$ e, em seguida, foi congelada para posterior determinação da amônia, segundo técnica de Fenner (1965), adaptada por Vieira (1980).

No 70 dia de cada período, foi fornecida uma única dose de $20 \mathrm{~g}$ de óxido cromo $\left(\mathrm{Cr}_{2} \mathrm{O}_{3}\right)$ para as vacas de dois quadrados latinos, totalizando oito animais, para determinação da taxa de passagem de sólidos. As amostras de fezes foram coletadas diretamente no reto dos animais, de acordo com o seguinte cronograma: imediatamente antes do fornecimento do óxido cromo e de $3 \mathrm{em} 3$ horas no primeiro dia; de 6 em 6 horas no segundo dia; e de $12 \mathrm{em}$ 12 horas nos três dias seguintes, perfazendo 19 amostras para cada animal.

O cálculo da taxa de passagem de sólidos e o tempo de retenção de sólidos no rúmen e nos intestinos foi feito utilizando-se o modelo bicompartimental, proposto por Grovum \& Williams (1973), ajustado às curvas de excreção fecal de cromo. Para o cálculo do tempo médio de retenção total da digesta (TMRT), utilizou-se a fórmula descrita por Hartnell \& Satter (1979): TMRT $=\left(\mathrm{TT}+1 / \mathrm{K}_{1}+1 / \mathrm{K}_{2}\right)$, em que $\mathrm{TT}=$ tempo calculado que o indicador aparece pela primeira vez nas fezes; $\mathrm{K}_{1}=$ taxa de passagem da digesta pelo rúmen; $\mathrm{K}_{2}=$ taxa de passagem pós-ruminal ou nos intestinos.

Os parâmetros do modelo foram estimados utilizando-se o procedimento de regressão não-linear de Gauss-Newton, do programa SAEG, versão 7.0 (UFV, 1997).

O preparo das amostras dos alimentos, das sobras e das fezes e as análises da MS, MO, PB, EE, FDN, FDA, LIG e MM foram feitos conforme descrito por Silva (1990). As análises

Tabela 1- Proporção dos ingredientes nas dietas experimentais, com base da matéria seca Table 1 - Ingredient composition of the experimental diets, dry matter basis

\begin{tabular}{|c|c|c|c|c|}
\hline \multirow[b]{2}{*}{ Ingrediente $(\%)$ (Ingredient) } & \multicolumn{4}{|c|}{$\operatorname{Dieta}^{1}$ (Diet) } \\
\hline & 0 & 33,3 & 66,6 & 100 \\
\hline Milho (Corn grain) & 25,4 & 24,4 & 23,4 & 22,4 \\
\hline Farelo de soja (Soybean meal) & 12,5 & 13,4 & 14,4 & 15,3 \\
\hline Uréia $^{2}$ (Urea) & 0,93 & 1,05 & 1,18 & 1,30 \\
\hline Fosfato bicálcico (Dicalcium phosphate) & 0,48 & 0,48 & 0,43 & 0,40 \\
\hline Calcário (Limestone) & 0,28 & 0,26 & 0,24 & 0,24 \\
\hline Sal comum (Salt) & 0,36 & 0,36 & 0,36 & 0,36 \\
\hline Premix mineral ${ }^{3}$ (Mineral premix) & 0,008 & 0,008 & 0,008 & 0,008 \\
\hline Silagem de milho (Corn silage) & 60,0 & 40,0 & 20,0 & 0 \\
\hline Cana-de-açúcar (Sugarcane) & 0 & 20,0 & 40,0 & 60,0 \\
\hline
\end{tabular}


de cromo foram feitas por espectrofotometria de absorção atômica, conforme metodologia de Williams et al. (1962).

Os dados obtidos foram submetidos às análises de variância e regressão, utilizando-se o programa SAEG, versão 7.0 (UFV, 1997), considerando-se quatro tratamentos $(0 ; 33,3 ; 66,6$ e $100 \%$ de substituição da silagem de milho pela cana-de-açúcar, na matéria seca) e três quadrados latinos 4 x 4 . Analisada a significância nos níveis de 1 e 5\%, as equações foram empregadas para determinação do melhor nível de substituição.

A variável taxa de passagem foi analisada pelo mesmo modelo, considerando apenas dois quadrados latinos.

Os dados de concentração de amônia e pH do líquido ruminal foram analisados por meio de um delineamento em blocos casualisados, em esquema de parcelas subdivididas, em que os tratamentos foram as parcelas e os quatro tempos de amostragem, as subparcelas.

\section{Resultados e Discussão}

As composições bromatológicas médias dos concentrados, em cada tratamento, da silagem de milho e da canade-açúcar são apresentadas na Tabela 2 e as composições das quatro dietas, na Tabela 3.

Os consumos médios de todos os nutrientes diminuíram $(\mathrm{P}<0,01)$ à medida que a silagem de milho foi substituída pela cana-de-açúcar (Tabela 4), à exceção dos consumos de LIG e CNF ( $\mathrm{P}>0,05)$, presentes em maior proporção na cana-de-açúcar. A redução no consumo de MS foi de $0,03 \mathrm{~kg}$ para cada unidade de silagem de milho substituída por cana-de-açúcar, chegando a $13,8 \%$ no maior nível de substituição.
As reduções nos consumos de MM, EE, NDT, FDN e FDA decorreram não somente da menor ingestão de MS, com o aumento da utilização da cana-de-açúcar, mas também das menores participações desses nutrientes nas composições químicas das dietas (Tabela 3).

O efeito redutor da cana-de-açúcar no consumo não apresentou relação direta com o teor de FDN das dietas, visto que esse componente diminuiu com o aumento da proporção de cana-de-açúcar. A variedade utilizada (SP-801842) é precoce e, segundo a tabela de Pate \& Coleman (1975) adaptada por Rodrigues (1999), possui valores considerados médios a baixos, para FDN e LIG $(47,0$ e 5,0\%, respectivamente). Entretanto, Fernandes et al. (2003a) propuseram o uso preferencial de variedades intermediárias para alimentação animal, em decorrência dos menores teores de FDN, FDA, da menor repleção ruminal total e da taxa de degradação da FDN, em comparação às variedades precoces.

A ingestão de MS é afetada quando bovinos consomem forragens de qualidades diferentes, independentemente da estratégia de alimentação. Então, torna-se evidente que a digestibilidade da fibra exerce grande efeito no consumo de MS (Allen, 1991), ou seja, o consumo é função da fração indigestível da dieta (Conrad, 1966). A cana-deaçúcar tem sido correlacionada negativamente à ingestão de matéria seca, não apenas pela fração indigestível da fibra, mas também pela baixa taxa de digestão da fibra potencialmente degradável, as quais apresentam elevado efeito de repleção ruminal (Pereira et al., 2000).

Os consumos médios de FDN para as dietas com $0 ; 33,3$ e $66,6 \%$ de substituição estão de acordo com os descritos por Mertens (1994), segundo o qual o consumo de FDN de $1,2 \pm 0,1 \%$ do peso corporal maximiza a produção de leite

Tabela 2 - Teores médios de MS, MM, MO, PB, NNP, EE, CT, FDN, CNF, FDA e LIG dos concentrados, da silagem de milho e da cana-deaçúcar

Table 2 - $\quad$ Average contents of DM, ash, OM, CP, NPN, EE, TC, NDF, NFC, ADF and LIG of the concentrates, corn silage and sugarcane

\begin{tabular}{|c|c|c|c|c|c|c|}
\hline \multirow[t]{2}{*}{$\begin{array}{l}\text { Nutriente } \\
\text { Nutrient }\end{array}$} & \multicolumn{4}{|c|}{$\begin{array}{l}\text { Concentrado } \\
\text { Concentrate }\end{array}$} & \multirow[t]{2}{*}{$\begin{array}{l}\text { Silagem de milho } \\
\text { Corn silage }\end{array}$} & \multirow[t]{2}{*}{$\begin{array}{c}\text { Cana-de-açúcar } \\
\text { Sugarcane }\end{array}$} \\
\hline & 0 & 33,3 & 66,6 & 100 & & \\
\hline $\mathrm{MS}^{1}(D M)$ & 87,60 & 87,60 & 87,60 & 87,60 & 28,57 & 30,97 \\
\hline $\mathrm{MM}^{2}(A s h)$ & 5,52 & 5,45 & 5,59 & 5,44 & 4,36 & 2,42 \\
\hline $\mathrm{MO}^{2}(\mathrm{OM})$ & 94,47 & 94,54 & 94,40 & 94,55 & 95,63 & 97,57 \\
\hline $\mathrm{PB}^{2}(C P)$ & 28,09 & 29,52 & 31,67 & 34,60 & 6,78 & 2,26 \\
\hline $\mathrm{NNP}^{3}(N P N)$ & 31,54 & 28,03 & 29,56 & 31,18 & 52,03 & 26,12 \\
\hline $\mathrm{EE}^{2}(E E)$ & 3,59 & 3,38 & 3,20 & 3,01 & 2,93 & 1,23 \\
\hline $\mathrm{CT}^{2}(T C)$ & 62,80 & 61,65 & 59,54 & 56,95 & 85,93 & 94,09 \\
\hline $\mathrm{FDN}^{2}(N D F)$ & 13,25 & 13,70 & 12,69 & 13,58 & 56,97 & 46,99 \\
\hline $\mathrm{CNF}^{2}(\mathrm{NFC})$ & 49,52 & 47,92 & 46,82 & 43,34 & 28,93 & 47,07 \\
\hline $\mathrm{FDA}^{2}(A D F)$ & 4,23 & 4,87 & 4,20 & 4,83 & 29,75 & 27,96 \\
\hline $\mathrm{LIG}^{2}$ & 0,70 & 1,06 & 0,91 & 0,80 & 3,48 & 5,02 \\
\hline
\end{tabular}

$1 \%$

$2 \%$ na MS (\% of DM).

$3 \%$ do nitrogênio total (\% of total nitrogen). 
Tabela 3 - Teores médios de MS, MM, MO, PB, NNP, EE, CT, FDN, CNF, FDA, LIG e NDT para as quatro dietas experimentais

Table 3 - $\quad$ Average contents of DM, ash, OM, CP, NPN, EE, TC, NDF, NFC, ADF, LIG and TDN for the four experimental diets

\begin{tabular}{|c|c|c|c|c|}
\hline \multirow[t]{2}{*}{$\begin{array}{l}\text { Item } \\
\text { Item }\end{array}$} & \multicolumn{4}{|c|}{$\begin{array}{c}\text { Dieta } \\
\text { Diet }\end{array}$} \\
\hline & 0 & 33,3 & 66,6 & 100 \\
\hline $\mathrm{MS}^{1}(D M)$ & 53,63 & 53,14 & 52,66 & 52,18 \\
\hline $\mathrm{MM}^{2}(A s h)$ & 4,83 & 4,41 & 4,08 & 3,63 \\
\hline $\mathrm{MO}^{2}(O M)$ & 95,16 & 95,58 & 95,91 & 96,37 \\
\hline $\mathrm{PB}^{2}(C P)$ & 15,31 & 14,97 & 14,93 & 15,19 \\
\hline $\mathrm{NNP}^{3}(N P N)$ & 37,17 & 32,78 & 31,40 & 30,64 \\
\hline $\mathrm{EE}^{2}(E E)$ & 3,20 & 2,77 & 2,36 & 1,94 \\
\hline $\mathrm{CT}^{2}(T C)$ & 76,66 & 77,85 & 78,63 & 79,24 \\
\hline $\mathrm{FDN}^{2}(N D F)$ & 39,48 & 37,67 & 35,27 & 33,63 \\
\hline $\mathrm{CNF}^{2}(\mathrm{NFC})$ & 37,17 & 40,16 & 43,34 & 45,58 \\
\hline $\mathrm{FDA}^{2}(A D F)$ & 19,54 & 19,44 & 18,82 & 18,71 \\
\hline Lignina $^{2}$ (Lignin) & 2,37 & 2,82 & 3,07 & 3,33 \\
\hline $\mathrm{NDT}^{2}(T D N)$ & 68,76 & 68,19 & 63,98 & 61,80 \\
\hline
\end{tabular}

$1 \%$

$2 \%$ na MS (\% of DM)

$3 \%$ do nitrogênio total (\% of total nitrogen). corrigida para $4 \%$ de gordura. Apenas o consumo de FDN para a dieta com $100 \%$ de cana-de-açúcar no volumoso foi inferior ao recomendado, o que também foi observado por Mendonça et al. (2004), ao testarem dietas contendo canade-açúcar como volumoso exclusivo (entre 0,9 e 1,0\% do peso corporal).

Valvasori et al. (1995) avaliaram níveis de substituição de silagem de milho por cana-de-açúcar em vacas com produções médias diárias em torno de $19 \mathrm{~kg}$ de leitee, embora não tenham encontrado diferenças significativas no total de MS ingerida, notaram diferenças quanto ao consumo de volumosos $(12,10 ; 10,19$ e $7,73 \mathrm{~kg}$ de MS/dia para os níveis de substituição de 0,50 e 100\%), justificando que o maior teor de lignina da cana-de-açúcar pode ter afetado o consumo.

Não foram observadas diferenças nos coeficientes de digestibilidade (CD) da MS, MO e PB $(\mathrm{P}>0,05)$ (Tabela 5). Entretanto, os CD do EE e FDN diminuíram linearmente

Tabela 4 - Médias, equações de regressão (ER) e coeficientes de variação (CV) e determinação $\left(R^{2}\right)$ para os consumos diários de $M S$, $\mathrm{MM}, \mathrm{MO}, \mathrm{NDT}, \mathrm{PB}, \mathrm{EE}, \mathrm{CT}, \mathrm{CNF}, \mathrm{FDN}$, FDA e LIG, conforme os níveis de cana-de-açúcar no volumoso

Table 4 - Means, regression equations (RE), coefficients of variation (CV) and determination $\left(R^{2}\right)$ of daily intakes of DM, ash, OM, TDN, CP, EE, TC, NFC, $N D F, A D F$, and $L I G$ according to the incremental levels of sugarcane in the diet

\begin{tabular}{|c|c|c|c|c|c|c|c|}
\hline \multirow[t]{2}{*}{$\begin{array}{l}\text { Consumo } \\
\text { Intake }\end{array}$} & \multicolumn{4}{|c|}{$\begin{array}{c}\text { Dieta } \\
\text { Diet }\end{array}$} & \multirow[b]{2}{*}{$\mathrm{ER}(R E)$} & \multirow[b]{2}{*}{ CV $(\%)$} & \multirow[b]{2}{*}{$\mathrm{R}^{2}$} \\
\hline & 0 & 33,3 & 66,6 & 100 & & & \\
\hline $\operatorname{MS}(\mathrm{kg} / \mathrm{dia})(D M, \mathrm{~kg} /$ day $)$ & 20,03 & 19,07 & 18,53 & 17,26 & $1 * *$ & 6,43 & 0,98 \\
\hline $\operatorname{MS}\left(\% \mathrm{PV}^{1}\right)(D M, \% B W)$ & 3,69 & 3,51 & 3,44 & 3,27 & $2 * *$ & 6,58 & 0,98 \\
\hline $\operatorname{MS}\left(\mathrm{g} / \mathrm{kg} \mathrm{PV}{ }^{0,75}\right)\left(D M, g / k g B W^{0.75}\right)$ & 177,90 & 169,42 & 165,69 & 156,80 & $3 * *$ & 6,51 & 0,98 \\
\hline MM (kg/dia) (Ash, kg/day) & 0,97 & 0,84 & 0,76 & 0,63 & $4 * *$ & 6,43 & 0,99 \\
\hline MO (kg/dia) $(O M, k g / d a y)$ & 19,06 & 18,23 & 17,77 & 16,63 & $5 * *$ & 6,73 & 0,97 \\
\hline $\operatorname{NDT}(\mathrm{kg} / \mathrm{dia})(T D N, \mathrm{~kg} /$ day $)$ & 13,45 & 12,82 & 11,87 & 10,92 & $6 * *$ & 9,23 & 0,99 \\
\hline $\mathrm{PB}(\mathrm{kg} / \mathrm{dia})(C P, \mathrm{~kg} /$ day $)$ & 3,18 & 2,99 & 3,02 & 2,85 & $7 * *$ & 6,44 & 0,85 \\
\hline $\mathrm{EE}(\mathrm{kg} / \mathrm{dia})(E E, \mathrm{~kg} /$ day $)$ & 0,64 & 0,53 & 0,44 & 0,34 & $8 * *$ & 6,78 & 1,00 \\
\hline $\mathrm{CT}(\mathrm{kg} / \mathrm{dia})(T C, \mathrm{~kg} /$ day $)$ & 15,24 & 14,70 & 14,30 & 13,37 & $9 * *$ & 7,00 & 0,97 \\
\hline CNF (kg/dia) (NFC, kg/day) & 7,85 & 8,02 & 8,48 & 8,23 & $\mathrm{~ns}$ & 7,07 & \\
\hline FDN (kg/dia) (NFD, kg/day) & 7,38 & 6,67 & 5,82 & 5,15 & $10 * *$ & 7,27 & 1,00 \\
\hline FDN $(\% \quad \mathrm{PV})(N F D, \% B W)$ & 1,23 & 1,23 & 1,08 & 0,98 & $11 *$ & 20,46 & 0,90 \\
\hline $\mathrm{FDN}\left(\mathrm{g} / \mathrm{kg} \mathrm{PV}{ }^{0,75}\right)\left(N F D, g / k g B W^{0.75}\right)$ & 65,56 & 59,30 & 52,05 & 46,81 & $12 * *$ & 7,25 & 1,00 \\
\hline FDA $(\mathrm{kg} / \mathrm{dia})(A D F, k g /$ day $)$ & 3,68 & 3,48 & 3,15 & 2,92 & $13 * *$ & 7,31 & 0,99 \\
\hline Lignina (kg/dia) (Lignin, $\mathrm{kg} /$ day) & 0,52 & 0,52 & 0,50 & 0,46 & $\mathrm{~ns}$ & 12,42 & \\
\hline
\end{tabular}

$1 \mathrm{PV}=$ peso vivo $(B W=$ body weight).

$X=$ Nível de cana-de-açúcar no volumoso, na base seca (\%).

** Significativo a $1 \%$, * Significativo a $5 \%$.

ns não-significativo a $5 \%$.

$X=L$ evel of sugarcane in the forage portion of the diet, in dry matter basis (\%).

** Significant at $1 \%$ level, * Significant at $5 \%$ level.

ns not significant at $5 \%$ level.

$1 Y=20,0548-0,0265735 X$

$8 Y=0,639795-0,00299494 X$

$\mathrm{Y}=3,67622-0,0039336 \mathrm{X}$

$9 \quad \mathrm{Y}=15,3097-0,0179708 \mathrm{X}$

$\mathrm{Y}=177,506-0,201156 \mathrm{X}$

$10 Y=7,39243-0,022692 X$

$\mathrm{Y}=0,967276-0,0032829 \mathrm{X}$

$11 \hat{Y}=1,26509-0,00270902 X$

$5 \mathrm{Y}=19,0996-0,0238282 \mathrm{X}$

$12 \mathrm{Y}=65,4561-0,190523 \mathrm{X}$

$\mathrm{Y}=13,5446-0,0255483 \mathrm{X}$

$13 \mathrm{Y}=3,70749-0,00793237 \mathrm{X}$

$7 \quad \mathrm{Y}=3,15707-0,00286211 \mathrm{X}$ 
( $\mathrm{P}<0,01)$, assim como o dos $\mathrm{CT}(\mathrm{P}<0,05)$ e o dos $\mathrm{CNF}(\mathrm{P}<0,01)$ aumentaram linearmente com o aumento da participação da cana-de-açúcar nas dietas.

O maior conteúdo de lignina na cana-de-açúcar pode ter afetado a proporção de FDN indigestível, além da taxa e da extensão da digestão da FDN potencialmente digestível das dietas. Segundo Hoover (1986), a concentração e a forma como a lignina está presente nas forragens podem ser parcialmente responsáveis pelas diferenças na digestão da fibra entre vários alimentos. Pode-se inferir, portanto, que a cana-de-açúcar apresentou elevada proporção de fibra indigestível em comparação à silagem de milho, uma vez que o coeficiente de digestibilidade da FDN para a dieta com $100 \%$ de cana-de-açúcar correspondeu a apenas $45,35 \%$ do valor obtido para a dieta com $100 \%$ de silagem de milho. A baixa digestão da FDN da cana-de-açúcar pode ter apresentado efeito de repleção ruminal e, conseqüentemente, limitado a ingestão de MS.

Boin et al. (1983) determinaram, em bovinos, os coeficientes de digestibilidade da silagem de milho e cana-deaçúcar, acrescida de dois níveis de concentrados (14 e 40\% da MS da dieta) e farelo de soja para elevar o teor de PB dos volumosos para 13\%. Esses autores não observaram efeitos do tipo de volumoso e do nível de concentrado para os coeficientes de digestibilidade da MS $(65,58 \%)$ e da MO $(69,29 \%)$. O tipo de volumoso influenciou os coeficientes de digestibilidade da $\mathrm{FB}$, do $\mathrm{EE}$ e dos $\mathrm{CNF}$, os quais apresentaram valores de 56,0 e $41,7 \%$; 82,7 e $74,9 \%$; e 68,6 e 74,4\%, respectivamente, para as dietas contendo silagem de milho e cana-de-açúcar. Entretanto, os conteúdos de NDT (67,3\%) não foram significativamente afetados pelo tipo de volumoso e pelo nível de concentrado.

Ludovico \& Mattos (1997) avaliaram dietas à base de cana-de-açúcar e farelo ou caroço de algodão para bovinos utilizando relação volumoso:concentrado de 66,3:33,7. Os coeficientes de digestibilidade da MS mantiveram-se entre 64 e $68 \%$ e os da MO, entre 65 e $69 \%$, ligeiramente acima dos obtidos neste trabalho. Porém, os níveis de consumo de MS foram inferiores $\left(70\right.$ a $\left.104 \mathrm{~g} / \mathrm{kg} \mathrm{PV}^{0,75}\right)$ e o coeficiente de digestibilidade da FDN esteve muito acima (40 a 49\%).

Constam na Tabela 6 os valores de pH e concentração de amônia do líquido ruminal. $\mathrm{O}$ pH não foi influenciado pelos níveis de cana-de-açúcar nas dietas $(\mathrm{P}>0,05)$. Entretanto, houve efeito quadrático $(\mathrm{P}<0,01)$ nos tempos de coleta, sendo estimado valor mínimo de $\mathrm{pH}$ de 6,63 às 3,41 horas após a alimentação matinal. Segundo Hoover \& Stokes (1991), a faixa ótima de pH situa-se entre 6,7 e 7,1.

A uniformidade do $\mathrm{pH}$ ruminal registrada entre as diferentes dietas pode ser conseqüência da forma de fornecimento. Raun et al. (1962) e Faria \& Huber (1984) demonstraram que o uso de rações completas possibilitou um padrão mais constante de fermentação no rúmen.

Os dados obtidos neste trabalho corroboram os resultados encontrados por Valvasori et al. (1998), que, ao substituírem os mesmos volumosos em dietas (relação volumoso:concentrado de 59,4: 40,6) para bovinos fistulados, constataram valores de $\mathrm{pH}$ semelhantes para as diferentes dietas, porém mais baixos (aproximadamente 6,3).

Tabela 5 - Médias, equações de regressão (ER), coeficientes de variação $(C V)$, e determinação $\left(R^{2}\right)$ obtidos para os coeficientes de digestibilidade da MS, MO, PB, EE, CT, FDN e CNF

Table 5 - Means, regression equations (RE), coefficients of variation (CV) and determination $\left(R^{2}\right)$ of the digestibility coefficients of $D M, O M, C P, E E, T C$, NDF and NFC

\begin{tabular}{|c|c|c|c|c|c|c|c|}
\hline \multirow[t]{2}{*}{$\begin{array}{l}\text { Coeficiente de digestibilidade } \\
\text { Digestibility coefficient }\end{array}$} & \multicolumn{4}{|c|}{$\begin{array}{l}\text { Dieta } \\
\text { Diet }\end{array}$} & \multirow[b]{2}{*}{$\mathrm{ER}(R E)$} & \multirow[b]{2}{*}{ CV (\%) } & \multirow[b]{2}{*}{$\mathrm{R}^{2}$} \\
\hline & 0 & 33,3 & 66,6 & 100 & & & \\
\hline MS (DM) & 66,68 & 67,20 & 65,22 & 64,45 & $\mathrm{~ns}$ & 4,68 & \\
\hline $\mathrm{MO}(O M)$ & 68,16 & 68,58 & 66,76 & 65,93 & $\mathrm{~ns}$ & 4,52 & \\
\hline $\mathrm{PB}(C P)$ & 68,30 & 68,82 & 66,94 & 67,35 & $\mathrm{~ns}$ & 4,03 & \\
\hline $\mathrm{EE}(E E)$ & 79,79 & 78,70 & 71,11 & 70,37 & $1 * *$ & 12,08 & 0,88 \\
\hline $\mathrm{CT}(T C)$ & 70,28 & 65,99 & 66,23 & 65,57 & $2 *$ & 12,38 & 0,67 \\
\hline FDN $(N D F)$ & 45,09 & 40,82 & 30,17 & 20,45 & $3 * *$ & 20,38 & 0,97 \\
\hline $\mathrm{CNF}(N F C)$ & 88,74 & 90,87 & 91,46 & 94,32 & $4 * *$ & 1,82 & 0,95 \\
\hline
\end{tabular}

$X=$ Nível de cana-de-açúcar no volumoso, na base seca $(\%)$.

** Significativo a $1 \%$, * Significativo a $5 \%$.

ns não-significativo a $5 \%$.

$X=$ Level of sugarcane in the forage portion of the diet, in dry matter basis (\%).

** Significant at $1 \%$ level, * Significant at $5 \%$ level.

ns not significant at $5 \%$ level.

$1 \mathrm{Y}=80,3733-0,107526 \mathrm{X}$

$2 \hat{Y}=69,1012-0,041603 X$

$3 \mathrm{Y}=46,8201-0,253797 \mathrm{X}$

$4 \quad \mathrm{Y}=88,7579+0,0519492 \mathrm{X}$ 
Tabela 6 - Médias, equações de regressão (ER) e coeficientes de variação (CV) e determinação ( $\left.\mathrm{R}^{2}\right)$ para pH e concentração de amônia $\left(\mathrm{N}-\mathrm{NH}_{3}\right)$ no líquido ruminal, conforme os níveis de cana-de-açúcar no volumoso e os tempos após alimentação

Table 6 - Means, regression equations (RE), coefficients of variation ( $\mathrm{CV}$ ) and determination $\left(\mathrm{R}^{2}\right)$ obtained for ruminal $\mathrm{pH}$ and ammonia $\left(\mathrm{N}-\mathrm{NH}_{3}\right)$, according to the incremental levels of sugarcane in the diet and time after feeding

\begin{tabular}{|c|c|c|c|c|c|c|c|}
\hline \multirow[t]{2}{*}{$\begin{array}{l}\text { Item } \\
\text { Item }\end{array}$} & \multicolumn{4}{|c|}{$\begin{array}{c}\text { Dieta } \\
\text { Diet }\end{array}$} & \multirow[b]{2}{*}{$\mathrm{ER}(R E)$} & \multirow[b]{2}{*}{$\mathrm{CV}(\%)$} & \multirow[b]{2}{*}{$\mathrm{R}^{2}$} \\
\hline & 0 & 33,3 & 66,6 & 100 & & & \\
\hline $\mathrm{pH}$ & 6,75 & 6,68 & 6,76 & 6,78 & $\mathrm{~ns}$ & 4,30 & \\
\hline \multirow[t]{3}{*}{$\mathrm{N}-\mathrm{NH}_{3}(\mathrm{mg} / \mathrm{dL})$} & 13,95 & 10,93 & 8,57 & 11,82 & $1 * *$ & 35,88 & 0,92 \\
\hline & \multicolumn{4}{|c|}{$\begin{array}{c}\text { Tempo } \\
\text { Time }\end{array}$} & & & \\
\hline & 0 & 2 & 4 & 6 & & & \\
\hline $\mathrm{pH}$ & 6,87 & 6,71 & 6,60 & 6,79 & $2 * *$ & 4,30 & 0,93 \\
\hline $\mathrm{N}-\mathrm{NH}_{3}(\mathrm{mg} / \mathrm{dL})$ & 4,66 & 20,25 & 12,56 & 7,81 & $3 * *$ & 35,88 & 0,75 \\
\hline
\end{tabular}

$\mathrm{T}=$ Tempo em horas, após a alimentação matinal.

$X=$ Nível de cana-de-açúcar no volumoso, na base seca $(\%)$.

** Significativo a $1 \%$.

ns não-significativo a $5 \%$.

$T=$ Time after morning feeding, in hours.

$X=L$ evel of sugarcane in the forage portion of the diet, in dry matter basis (\%).

** Significant at $1 \%$ level.

ns not significant at $5 \%$ level.

$1 Y=14,197-0,167817 X+0,00141758 X^{2} \quad 2 \hat{Y}=6,88637-0,149208 T+0,021875 T^{2}$

$3 \mathrm{Y}=5,96989+7,71769 \mathrm{~T}-1,27151 \mathrm{~T}^{2}$

Esses autores também observaram efeito quadrático do $\mathrm{pH}$ quanto aos tempos de coleta. Mendonça et al. (2004) também não encontraram diferença nos valores de $\mathrm{pH}$ ruminal em vacas em lactação alimentadas com dietas contendo silagem de milho ou cana-de-açúcar como volumosos exclusivos e relação volumoso: concentrado de 60:40.

As concentrações médias de amônia situaram-se acima de $5 \mathrm{mg} / \mathrm{dL}$ de líquido ruminal para todos os tratamentos, o que garante boa atividade dos microrganismos ruminais e não limita seu crescimento (Satter \& Slyter, 1974). O fornecimento de dietas completas apresenta a vantagem de que a utilização do NNP pelas bactérias ruminais pode ser incrementada, em razão do parcelamento da dose e da ingestão lenta (Huber, 1984), além da disponibilidade maior e mais uniforme de $\mathrm{N}_{-} \mathrm{NH}_{3}$ no líquido ruminal (Faria, 1993).

As concentrações de amônia foram influenciadas pelas dietas e pelos tempos após a alimentação matinal $(\mathrm{P}<0,01)$, observando-se efeito quadrático dos níveis de cana-deaçúcar. A concentração mínima estimada foi de $9,23 \mathrm{mg} / \mathrm{dL}$, com 59,19\% de cana-de-açúcar no volumoso, e a máxima de $17,68 \mathrm{mg} / \mathrm{dL}$, registrada 3,03 horas após a refeição.

Na Tabela 7 encontram-se as estimativas das taxas de passagem ruminal (TPR) e dos TMRT. A TPR decresceu, enquanto o TMRT aumentou linearmente $(\mathrm{P}<0,05)$, estimando-se redução de 0,0057 unidades na TPR e aumento de 0,00375 unidades para o TMRT, respectivamente, por unidade percentual de cana-de-açúcar acrescentada às dietas.

Estimando-se o conteúdo de FDNi das dietas como FDNi (\%)= lignina $(\%) * 2,4$ (Mertens, 1996), à exceção da dieta com cana-de-açúcar como volumoso exclusivo, para a qual utilizou-se o fator de 4,38, proposto por Fernandes et al. (2003b), obtiveram-se os valores de 5,69; 8,76; 11,28 e $13,96 \%$, respectivamente, para as dietas com níveis crescentes de cana-de-açúcar. As taxas de digestão da FDN estimadas em $0,0357 \mathrm{~h}^{-1}$ para a silagem de milho (Cabral et al., 2000) e em $0,0227 \mathrm{~h}^{-1}$ para a cana-de-açúcar (Fernandes et al., 2003b), associadas às estimativas de FDNi das dietas, podem explicar a redução da TPR e o concomitante aumento do TMRT, uma vez que, embora os teores de FDN e FDA das dietas tenham diminuído à medida que se aumentou a participação da cana-de-açúcar nas dietas, houve reduções do consumo de MS, FDN e FDA pelos animais, bem como do coeficiente de digestibilidade da FDN.

O incremento do consumo freqüentemente resulta em taxas de passagem mais rápidas, tanto pelo rúmen como por todo o trato digestivo, o que também foi observado por Shellenberger \& Kesler (1961) e Colucci et al. (1982), ao estudarem a taxa de passagem da digesta pelo trato gastrintestinal de vacas em lactação. Colucci etal. (1982) encontraram valores para a TPR de $6,83 \% / \mathrm{h}$ e, para a TMRT de 39,8 horas, em vacas consumindo dietas completas com 37,81\% de FDN.

Os dados de TPR propostos pelo AFRC (1993), obtidos com a fórmula $\mathrm{r}=-0,024+0,179\left\{1-\mathrm{e}^{(-0,278 \mathrm{~L})}\right\}$, são 8,60 ; 8,$20 ; 7,50$ e $6,80 \% / \mathrm{h}$, para os níveis $0 ; 33,3 ; 66,6$ e $100 \%$ de cana-de-açúcar no volumoso, respectivamente:

em que $r$ = fluxo ruminal da digesta; $L$ = nível de alimentação como múltiplo de energia metabolizável(EM) para mantença, em Megajoule (MJ). 
Tabela 7 - Médias, equações de regressão (ER) e coeficientes de variação $(C V)$ e determinação $\left(R^{2}\right)$ obtidos para as estimativas de taxa de passagem ruminal (TPR) e dos tempos médios de retenção total da digesta (TMRT), conforme os níveis de cana-deaçúcar no volumoso

Table 7 - Means, regression equations (RE), coefficients of variation (CV) and determination $\left(R^{2}\right)$ obtained for ruminal passage rate (RPR) and total average retention time (TART) according to the incremental levels of sugarcane in the diet

\begin{tabular}{|c|c|c|c|c|c|c|c|}
\hline \multirow[t]{2}{*}{$\begin{array}{l}\text { Item } \\
\text { Item }\end{array}$} & \multicolumn{4}{|c|}{$\begin{array}{c}\text { Dieta } \\
\text { Diet }\end{array}$} & \multirow[b]{2}{*}{$\mathrm{ER}(R E)$} & \multirow[b]{2}{*}{ CV (\%) } & \multirow[b]{2}{*}{$\mathrm{R}^{2}$} \\
\hline & 0 & 33,3 & 66,6 & 100 & & & \\
\hline $\mathrm{TPR}(\% / \mathrm{h}) \quad(R P R)$ & 5,84 & 5,75 & 5,36 & 5,27 & $1 * *$ & 7,10 & 0,92 \\
\hline TMRT (h) (TART) & 36,16 & 36,71 & 39,27 & 39,91 & $2 * *$ & 6,74 & 0,93 \\
\hline
\end{tabular}

** Significativo a $1 \%$.

$X=$ Nível de cana-de-açúcar no volumoso, na base seca $(\%)$.

**Significant at $1 \%$ level.

$X=$ Level of sugarcane in the forage portion of the diet, in dry matter basis (\%).

$1 \hat{Y}=5,87167-0,0062847 \mathrm{X} \quad 2 \mathrm{Y}=35,9483+0,041428 \mathrm{X}$

Então, os resultados de TPR encontrados neste trabalho foram 2,$76 ; 2,45 ; 2,14$ e 1,53 unidades abaixo dos propostos pelo AFRC (1993) para os níveis 0; 33,3; 66,6 e 100\% de cana-de-açúcar no volumoso, respectivamente, o que indica ser relevante o fornecimento de volumosos com boa qualidade de fibra. Ressalta-se que os dados utilizados para obtenção das equações sugeridas pelo AFRC (1993) são provenientes de animais de maior potencial genético alimentados com forrageiras de maior valor nutritivo que as de clima tropical.

\section{Conclusões}

A substituição de silagem de milho por cana-de-açúcar em dietas completas e com $40 \%$ de concentrado para vacas em lactação com produções médias diárias de $24 \mathrm{~kg}$ de leite não comprometeu a utilização dos nutrientes e a estabilidade do rúmen. Entretanto, como ocorreu redução do consumo de nutrientes e das estimativas da taxa de passagem ruminal, recomenda-se limitar a quantidade a ser substituída em $33,3 \%$ da porção volumosa da dieta.

\section{Literatura Citada}

AGRICULTURAL AND FOOD RESEARCH COUNCIL - AFRC. Energy and protein requirements of ruminants. Cambridge: CAB International, 1993. 159p

ALLEN, M.S. Carbohydrate nutrition. The Veterinary Clinics of North America, v.7, n.2, p.327-340, 1991.

BOIN, C.; ALLEONI, G.F.; BIONDI, P. et al. Comparação entre silagem de milho e cana-de-açúcar na alimentação de ruminantes. 2. Efeito do nível de concentrado na produção de leite. In: REUNIÃO ANUAL DA SOCIEDADE BRASILEIRA DE ZOOTECNIA, 20., 1983, Pelotas. Anais... Pelotas: Sociedade Brasileira de Zootecnia, 1983. p.84.

COCHRAN, R.C.; ADAMS, D.C.; WALLACE, J.D. et al. Predicting digestibility of different diets with internal markers: Evaluation of four potential markers. Journal of Animal Science, v.63, n. 5, p. $1476-1483,1986$.
COLUCCI, P.E.; CHASE, L.E.; VAN SOEST, P.J. Feed intake, apparent diet digestibility, and rate of particulate passage in dairy cattle. Journal of Dairy Science, v. 65 , n.8, p.14451456, 1982.

CONRAD, H.R. Symposium on factors influencing the voluntary intake of herbage by ruminants. Physiological and physical factors limiting feeding intake. Journal of Animal Science, v. 25, p. $227-235,1966$

FARIA, V.P. Rações completas para vacas em lactação. In: PEIXOTO, A.M.; MOURA, J.C.; FARIA, V.P. (Eds.) Confinamento de bovinos leiteiros. Piracicaba: Fundação de Estudos Agrários Luiz de Queiroz, 1993. p.229-244.

FARIA, V.P.; HUBER, J.T. Effect of dietary protein and energy levels on rumen fermentation in Holstein steers. Journal of Animal Science, v.58, p.452-459, 1984.

FERNANDES, A.M.; QUEIROZ, A.C.; PEREIRA, J.C. et al. Composição químico-bromatológica de variedades de canade-açúcar (Saccharum spp L.) com diferentes ciclos de produção (precoce e intermediário) em três idades de corte. Revista Brasileira de Zootecnia, v.32, n.4, p.977-985, 2003 a.

FERNANDES, A.M.; QUEIROZ, A.C.; PEREIRA, J.C. et al. Fracionamento e cinética da degradação in vitro dos carboidratos constituintes da cana-de-açúcar com diferentes ciclos de produção em três idades de corte. Revista Brasileira de Zootecnia, v.32, n.6, p.1778-1785, 2003b. (supl. 1)

FERREIRA, A.M.; TORRES, C.A.A. Perda de peso corporal e cessação da atividade ovariana luteínica cíclica em vacas mestiças leiteiras. Pesquisa Agropecuária Brasileira, v.28, n.3, p.411-418, 1993.

GROVUM, W.L.; WILLIAMS, V.J. Rate of passage digesta in sheep. 3. Differential rates of passage of water and dry matter from the reticulo-rumen, abomasum and caecum and proximal colon. British Journal of Nutrition, v.30, p.231-240, 1973.

HARTNELL, G.F.; SATTER, L.D. Determination of rumen fill, retention time and ruminal turnover rates of ingesta at different stages of lactation in dairy cows. Journal of Animal Science, v.48, n.2, p.381-392, 1979.

HOOVER, W.H. Chemical factors involved in ruminal fiber digestion. Journal of Dairy Science, v.69, n.10, p.27552766, 1986.

HOOVER, W.H.; STOKES, S.R. Balancing carbohydrates and proteins for optimum rumen microbial yield. Journal of Dairy Science, v.74, n.12, p.3630-3644, 1991.

HUBER, J.T. Uréia ao nível do rúmen. In: SIMPÓSIO SOBRE NUTRIÇÃO DE BOVINOS, 2., 1984, Piracicaba. Anais... Piracicaba: Fundação de Estudos Agrários Luiz de Queiroz, 1984. p.78-96. 
KITESSA, S.; FLINN, P.C.; IRISH, G.G. Comparison of methods used to predict the in vivo digestibility of feeds in ruminants. Australian Journal of Agricultural Research, v.50, p.825$841,1999$.

LAVEZZO, O.E.N.M.; FARIA, V.P.; MATTOS, W.R.S. et al. Influência dos métodos de coleta do fluido ruminal sobre os parâmetros de fermentação em bovinos alimentados com diferentes fontes de proteína. Revista da Sociedade Brasileira de Zootecnia, v.17, n.2, p.281-291, 1988.

LUDOVICO, A.; MATTOS, W.R.S. Avaliação de dietas à base de cana-de-açúcar (Saccharum officinarum L.) e diferentes níveis de semente de algodão (Gossypium hirsutum L.). Revista Brasileira de Zootecnia, v.26, n.2, p.403-410, 1997.

MAGALHÃES, A.L.R.; CAMPOS, J.M.S.; VALADARES FILHO, S.C. et al. Cana-de-açúcar em substituição à silagem de milho em dietas para vacas em lactação: desempenho e viabilidade econômica. Revista Brasileira de Zootecnia, v.33, n.5, p.1292-1302, 2004.

MATOS, L.L. Perspectivas em alimentação e manejo de vacas em lactação. In: REUNIÃO ANUAL DA SOCIEDADE BRASILEIRA DE ZOOTECNIA, 32., 1995, Brasília. Anais... Brasília: Sociedade Brasileira de Zootecnia, 1995. p.147-155.

MENDONÇA, S.S.; CAMPOS, J.M.S.; VALADARES FILHO, S.C. et al. Consumo, digestibilidade aparente, produção e composição do leite e variáveis ruminais em vacas leiteiras alimentadas com dietas à base de cana-de-açúcar. Revista Brasileira de Zootecnia, v.33, n.2, p.481-492, 2004.

MERTENS, D.R. Regulation of forage intake. In: FAHEY JR. G.C. (Ed.) Forage quality, evaluation, and utilization. Lincoln: University of Nebraska, 1994. p.450-493.

MERTENS, D.R. Comparing forage sources in dairy rations containing similar neutral detergent fiber concentrations. In: U. S. Dairy Forage Research Center (Ed.) Research summaries. Wisconsin: USDA, ARS, 1996. p.87-90.

NATIONAL RESEARCH COUNCIL - NRC. Nutrient requeriments of dairy cattle. 6.ed. Washington, D.C.: Academic Press, 1989. 158p.

ORTOLONI, E.L. Considerações técnicas sobre o uso da sonda esofágica na colheita do suco de rúmen de bovinos para mensuração do pH. Arquivos da Escola de Veterinária, v.33, n.2, p.269-275, 1981

PEREIRA, E.S.; QUEIROZ, A.C.; PAULINO, M.F. et al. Determinação das frações protéicas e de carboidratos e taxas de degradação in vitro da cana-de-açúcar, da cama de frango e do farelo de algodão. Revista Brasileira de Zootecnia, v.29, n.6, p.1887-1893, 2000.

PRESTON, T.R. Nutritional limitations associated with the feeding of tropical forages. Journal of Animal Science, v.54, n.4, p. 877-884, 1982 .

QUEIROZ, A.C.; BARBOSA, M.A.; RESENDE, F.D. et al. Suplementação da palhadas de milho na alimentação de bovinos. 2. Concentração de amônia ruminal e pH ruminal. Revista Brasileira de Zootecnia, v.27, n.2, p.390-396, 1998.

RAUN, N.S.; BURRONGHS, W.; WORDS, W. Dietary factors affecting volatile fatty acids production in the rumen. Journal of Animal Science, v.21, p.838-844, 1962
RODRIGUES, A.A. Potencial e limitações de dietas à base de canade-açúcar e uréia para recria de novilhas e para vacas em lactação. In: SIMPÓSIO MINEIRO DE NUTRIÇÃO DE GADO DE LEITE, 2., 1999, Belo Horizonte. Anais... Belo Horizonte: 1999. p.65-75

RUSSEL, J.B.; WALLACE, R.J. Energy yielding and consuming reactions. In: ROBSON, P.N. (Ed.) The rumen microbial ecossystem. London: Chapman \& Hall, 1997, p.246-282.

SATTER, L.D.; SLYTER, L.L. Effect of ammonia concentration on rumen microbial protein production in vitro. British Journal of Nutrition, v.32, p.199-208, 1974.

SHELLENBERGER, P.R.; KESLER, E.M. Rate of passage of feeds through the digestive tract of Holstein cows. Journal of Animal Science, v. 20, p.416-419, 1961.

SILVA, D.J. Análise de alimentos (Métodos químicos e biológicos). Viçosa, MG: Universidade Federal de Viçosa, 1990. 165p.

SNIFFEN, C.J.; O'CONNOR, J.D.; Van SOEST, P.J. et al. A net carbohydrate and protein system for evaluating cattle diets: II. Carbohydrate and protein avaiability. Journal of Animal Science, v.70, n.10, p.3562-3577, 1992.

UNIVERSIDADE FEDERAL DE VIÇOSA - UFV. SAEG - Sistema de análises estatísticas e genéticas. Versão 7.1. Viçosa, MG: 1997. 150. (Manual do usuário).

VALVASORI, E.; LUCCI, C.S.L.; ARCARO, J.R.P. et al. Avaliação da cana-de-açúcar em substituição à silagem de milho para vacas leiteiras. Brazilian Journal of Veterinarian Research in Animal Science, v.32, n.4, p.224-228, 1995

VALVASORI, E.; LAVEZZO, W.; LUCCI. C.S. et al. Alterações na fermentação ruminal de bovinos fistulados alimentados com cana-de-açúcar em substituição à silagem de milho. In: REUNIÃO ANUAL DA SOCIEDADE BRASILEIRA DE ZOOTECNIA, 35., 1998, Botucatu. Anais... Botucatu: Sociedade Brasileira de Zootecnia, 1998, p.86-88.

Van SOEST, P.J. Nutritional ecology of the ruminant. 2.ed. Ithaca: Cornell University Press, 1994. 476p.

Van SOEST, P.J. Development of a comprehensive system of feed analyses and its application to forage. Journal of Animal Science, v.2, n.1, p.119-128, 1967

VIEIRA, P.F. Efeito do formaldeído na proteção de proteínas e lipídios em rações para ruminantes. Viçosa, MG: Universidade Federal de Viçosa, 1980. 98p. Tese (Doutorado em Zootecnia) - Universidade Federal de Viçosa, 1980.

WALlACE, R.J.; ONODERA, R.; COTTA, M.A. Metabolism of nitrogen-containing compounds. In: HOBSON, P.N.; STEWART, C.S. (Eds.) The rumen microbial ecosystem. 2.ed. London: Chapman \& Hall, p.283-328, 1997.

WILLIAMS, C.H.; DAVID, D.J.; IISMAA, O. The determination of chromic oxide in feces samples by atomic absorption spectrophotometry. Journal of Agricultural Science, v.59, p.381-385, 1962 .

Recebido: 03/12/03 Aprovado:22/11/05 